\title{
Improvement of impaired diastolic left ventricular function after diet-induced weight reduction in severe obesity
}

\author{
Sevda Karimian' \\ Juergen Stein² \\ Boris Bauer ${ }^{3}$ \\ Claudius Teupe' \\ 'Department of Medicine - \\ Cardiology, ${ }^{2}$ Department of \\ Medicine - Gastroenterology, \\ ${ }^{3}$ Department of Radiology, \\ Krankenhaus Sachsenhausen, Teaching \\ Hospital of Goethe University \\ Frankfurt, Frankfurt, Germany
}

This article was published in the following Dove Press journal:

Diabetes, Metabolic Syndrome and Obesity:Targets and Therapy

7 January 2017

Number of times this article has been viewed

Correspondence: Claudius Teupe Department of Internal Medicine Cardiology, Krankenhaus Sachsenhausen, Teaching Hospital of Goethe University Frankfurt, Schulstrasse 3I, D-60594

Frankfurt, Germany

Tel $+49696605 \quad$ II00

Fax +4969660529 II00

Email Teupe@em.uni-frankfurt.de

Background/objectives: Obesity is independently associated with left ventricular (LV) diastolic dysfunction and altered cardiac morphology. Morbidity and mortality in patients with diastolic dysfunction are similar to values observed in patients with systolic heart failure. We hypothesized that dysfunctional cardiac responses in people with obesity are reversible after weight loss. Thus, we studied the effect of dietary weight reduction on LV diastolic function as well as on cardiac structure using transthoracic echocardiography and tissue Doppler imaging (TDI).

Subjects/methods: Thirty-two subjects with obesity underwent a 12-week low-calorie fasting phase of a formula diet. Echocardiographic tissue Doppler indices of diastolic function and measurements of cardiac size were obtained prior to and after the fasting phase.

Results: A 12-week diet significantly reduced body mass index from $40.3 \pm 6.6 \mathrm{~kg} / \mathrm{m}^{2}$ to $33.2 \pm 6.1 \mathrm{~kg} / \mathrm{m}^{2}(p<0.01)$. Weight loss was associated with a significant reduction in blood pressure and heart rate. Echocardiography revealed diastolic dysfunction in subjects with obesity, which was improved by dieting. After weight loss, trans-mitral Doppler echocardiography showed a significant reduction in A-wave velocity, from $65.8 \pm 19.2 \mathrm{~cm} / \mathrm{s}$ to $57.0 \pm 16.8 \mathrm{~cm} / \mathrm{s}$, and an increase in $\mathrm{E} / \mathrm{A}$ ratio from $1.2 \pm 0.4$ to $1.4 \pm 0.5(p<0.01)$. TDI displayed a significantly lower $\mathrm{a}^{\prime}$-wave velocity $(10.3 \pm 2.3 \mathrm{~cm} / \mathrm{s}$ and $8.9 \pm 1.7 \mathrm{~cm} / \mathrm{s} ; p<0.01)$. Left atrial and LV dimensions were normal and remained unchanged after weight loss.

Conclusion: Obesity is associated with diastolic dysfunction. A 12-week low-calorie diet with successful weight loss can reduce blood pressure and heart rate and partially normalize diastolic dysfunction.

Keywords: adiposity, echocardiography, tissue Doppler imaging, diastolic function, weight loss

\section{Background}

Obesity and associated comorbidities such as hypertension and diabetes result in significant changes in the cardiovascular system. Currently, obesity is classified on the basis of body mass index (BMI), and patients with BMI $>30 \mathrm{~kg} / \mathrm{m}^{2}$ are considered obese. A BMI $>30 \mathrm{~kg} / \mathrm{m}^{2}$ is associated with premature atherosclerosis, increased risk of myocardial infarction, heart failure, and decreased survival. ${ }^{1,2}$ Although BMI is a useful predictor, other factors, including the adiposity distribution, degree of visceral or ectopic fat burden, and percentage of body fat, have an influence on clinical disease expression. ${ }^{3}$

Recent studies have demonstrated that obesity is associated with cardiac dysfunction. In several echocardiographic studies, the presence of mild systolic and diastolic dysfunction in obese individuals has been reported. ${ }^{4,5}$ Morbidity and mortality in patients with diastolic dysfunction are similar to values observed in patients with 
systolic heart failure. ${ }^{6}$ Importantly, these alterations in cardiovascular structure and function have also been shown to be reversible with weight loss strategies such as bariatric surgery resulting in a decreased cardiovascular risk. ${ }^{7-10}$

We hypothesized that dysfunctional cardiac responses in obese subjects are reversible after substantial weight loss via a low-calorie diet program. Thus, we studied the effect of weight reduction on left ventricular (LV) diastolic function as well as on cardiac structure using transthoracic echocardiography (TTE) and tissue Doppler imaging (TDI).

\section{Methods}

Ethical approval for the study was obtained from the Ethics Committee of the State Medical Association (approval number FF 112/2015). All participants provided written informed consent.

\section{Patient population and study design}

Initially, 54 patients were included in the study. All patients were participants in the OPTIFAST ${ }^{\circledR}-52$ diet program (Nestlé Health Science, Frankfurt, Germany). The study design has previously been described in detail. ${ }^{11}$ Briefly, the 52-week program included a fasting phase of 12 weeks with food ingestion restricted to formula products with a high protein content (total calorie intake approximately $800 \mathrm{kcal}$ per day). A subsequent transitional phase and a final stabilization phase aimed to introduce the patients to a balanced diet. All patients received psychological, physiotherapeutic, medical, and nutritional care. Finally, 32 patients were evaluated. Twenty-two patients withdrew from the study, discontinuing the diet plan prematurely for personal reasons (Figure 1).

Inclusion criteria were as follows: 1 ) age $\geq 18$ years and $\leq 65$ years; 2) BMI $>30 \mathrm{~kg} / \mathrm{m}^{2} ; 3$ ) presence of secondary and concomitant conditions requiring treatment, such as hypertension, hypercholesterolemia, diabetes mellitus, and locomotor system disorders; 4) medical certification of the necessity for participation in the program; and 5) participants had to have made at least three previous unsuccessful attempts to reduce weight. Exclusion criteria were cardiac arrhythmia, history of myocardial infarction, severe (malign) general illnesses, pregnancy and nursing, or a documented eating disorder.

Clinical measurements were performed once a week. Echocardiography was performed at week 1 and week 12 . In addition, total body composition and fat content were measured using dual-energy X-ray absorptiometry (DXA) at week 1 and week 12 .

\section{Transthoracic echocardiography (TTE)}

Echocardiography was performed using a commercially available ultrasound machine (Vivid 7; GE Healthcare, Little Chalfont, UK) and a $3.5 \mathrm{MHz}$ (3S-RS) transducer. Patients were examined in a resting, left-lateral position and, for specific parts of the examination, in end-expiration by an experienced examiner. All images were obtained from standard parasternal and apical position using two-dimensional, M-mode, and Doppler echocardiographic techniques. Pulse

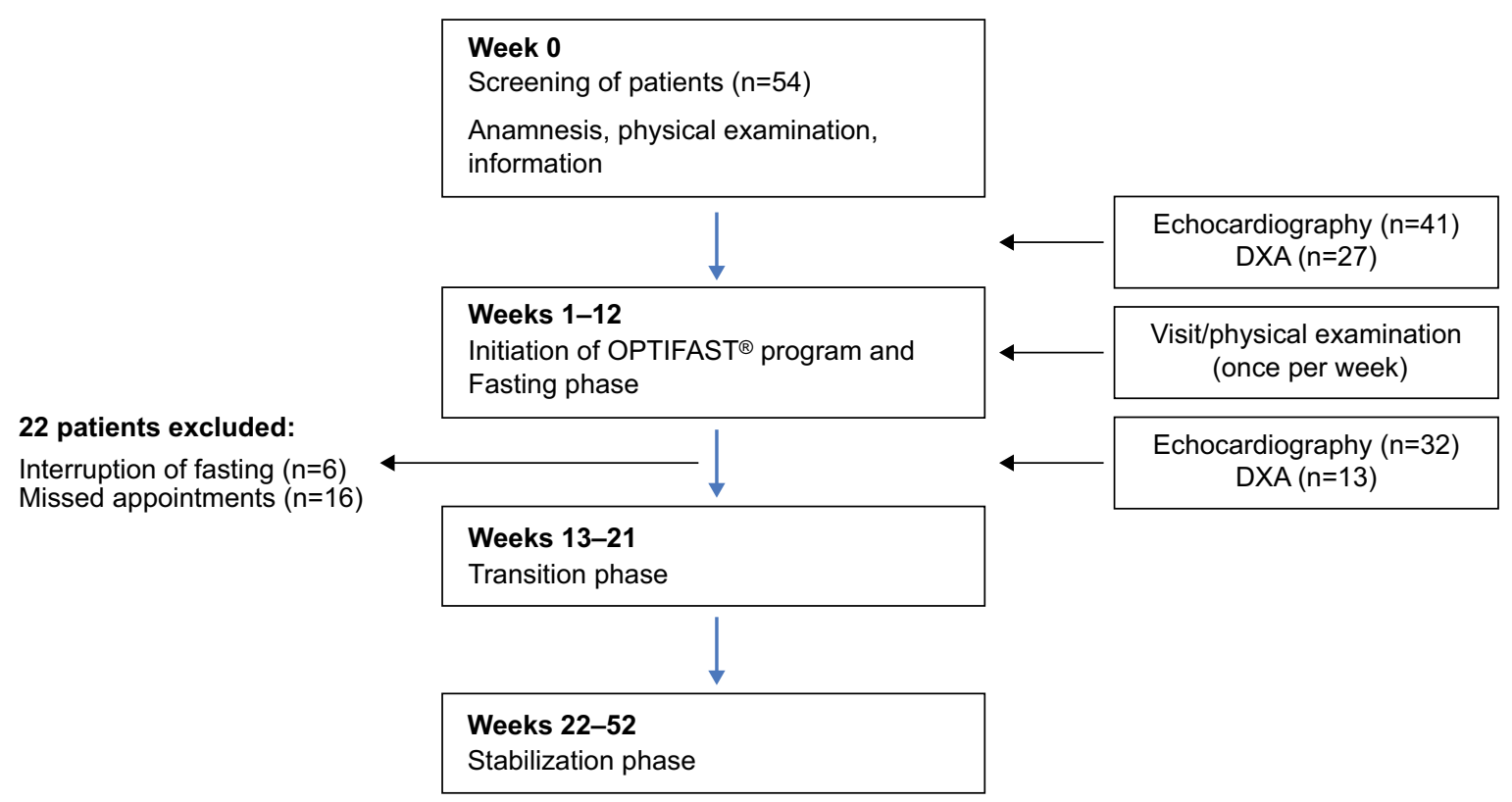

Figure I Study flow diagram.

Abbreviation: DXA, dual-energy X-ray absorptiometry. 
Doppler sample volume was placed at the mitral valve tips in the apical four-chamber view to record trans-mitral LV inflow velocity. Diastolic LV filling normally consists of an early passive filling phase (E) and late active filling with atrial contraction phase (A), where the E-wave is greater than the A-wave and the E/A ratio is positive. When the ventricle becomes noncompliant, the E-wave is reduced, and the $\mathrm{A}$-wave increases resulting in a reversal of the $\mathrm{E} / \mathrm{A}$ ratio.

\section{TDI}

TDI was recorded from the apical four-chamber view. The pulsed-wave Doppler volume was placed on the septal corner of the mitral annulus. Care was taken to ensure that the ultrasound beam was parallel to the direction of the mitral annulus motion. Filters and gains were set to exclude highfrequency signals and to obtain clear tissue signals. Peak early $\left(\mathrm{e}^{\prime}\right)$ and late $\left(\mathrm{a}^{\prime}\right)$ diastolic mitral septum annular velocities were measured. Each parameter was measured three times, and these values were averaged. Indices derived from TDI, including $\mathrm{e}^{\prime}$ and $\mathrm{a}^{\prime}$ velocities of the mitral annulus, were reduced in heart failure patients. ${ }^{12}$

\section{DXA}

DXA is a common measurement of human body composition. It divides the body into total body mineral, fat-free soft mass and fat tissue mass. Measurements were taken with the patient lying in the supine position on the scanning table. By means of the appropriate software, information on the body composition was obtained from the whole-body scan (Hologic densitometer QDR Discovery Wi; Hologic Inc., Bedford, MA, USA).

\section{Statistical analysis}

Continuous variables are expressed as mean and standard deviation. For the descriptive statistics, the arithmetic mean, minimum, and maximum were calculated. For the comparison of two measurements at different times, the Wilcoxon matched pairs test was applied for paired samples. Analysis was done using statistical software (BiAS for Windows, Version 11.0). $p$-Values less than 0.05 were reported as statistically significant.

\section{Results}

\section{Clinical characteristics}

The study included 32 patients. Clinical characteristics of the study population are presented in Table 1 .

After the 12-week diet, body weight was significantly reduced from $124.7 \pm 27.3 \mathrm{~kg}$ to $102.5 \pm 24.4 \mathrm{~kg}(p<0.01)$. The mean percentage weight loss was $18 \pm 5 \%$ of baseline
Table I Baseline characteristics $(n=32)$

\begin{tabular}{ll}
\hline Sex (female/male) & $20 / 12$ \\
Age (years) & $44.5 \pm 8.6$ \\
Height $(\mathrm{cm})$ & $175.3 \pm 10.6$ \\
Hypertension & $15(47 \%)$ \\
Hyperlipidemia & $5(16 \%)$ \\
Diabetes mellitus & $6(19 \%)$ \\
Smoking & $3(9 \%)$ \\
\hline
\end{tabular}

Note: Data are presented as mean \pm standard deviation or number (\%).

Table 2 Changes in blood pressure, medication, and metabolic parameters

\begin{tabular}{|c|c|c|c|}
\hline Characteristics & Week I & Week I2 & $p$-Value \\
\hline \multicolumn{4}{|l|}{ Blood pressure and heart rate } \\
\hline Systolic blood pressure $(\mathrm{mmHg})$ & $146 \pm 14$ & $130 \pm 15$ & $<0.01$ \\
\hline Diastolic blood pressure $(\mathrm{mmHg})$ & $93 \pm 12$ & $83 \pm 9$ & $<0.01$ \\
\hline Heart rate (beats per minute) & $90 \pm 15$ & $80 \pm 13$ & $<0.01$ \\
\hline \multicolumn{4}{|l|}{ Medication } \\
\hline ACE inhibitors & $4(12 \%)$ & $3(9 \%)$ & 0.84 \\
\hline Angiotensin receptor blockers & $6(18 \%)$ & $2(6 \%)$ & 0.40 \\
\hline$\beta$-Blockers & $7(21 \%)$ & I (3\%) & 0.20 \\
\hline Calcium channel blockers & $\mathrm{I}(3 \%)$ & $0(0 \%)$ & 0.84 \\
\hline Hydrochlorothiazide & $4(12 \%)$ & I (3\%) & 0.53 \\
\hline \multicolumn{4}{|l|}{ Metabolic parameter } \\
\hline Glucose (mg/dL) & $106 \pm 38$ & $91 \pm 30$ & $<0.05$ \\
\hline Total cholesterol (mg/dL) & $225 \pm 38$ & $173 \pm 32$ & $<0.01$ \\
\hline LDL-cholesterol (mg/dL) & $147 \pm 33$ & $106 \pm 33$ & $<0.01$ \\
\hline HDL-cholesterol (mg/dL) & $57 \pm 13$ & $56 \pm 15$ & 0.54 \\
\hline Triglyceride $(\mathrm{mg} / \mathrm{dL})$ & $156 \pm 69$ & $97 \pm 29$ & $<0.01$ \\
\hline Uric acid $(\mathrm{mg} / \mathrm{dL})$ & $6.2 \pm 1.7$ & $5.4 \pm 1.5$ & 0.06 \\
\hline
\end{tabular}

Note: Data are presented as mean \pm standard deviation or number (\%).

Abbreviations: ACE, angiotensin-converting enzyme; LDL, low-density lipoprotein; HDL, high-density lipoprotein.

weight. BMI was also significantly reduced, from $40.3 \pm$ $6.6 \mathrm{~kg} / \mathrm{m}^{2}$ to $33.2 \pm 6.1 \mathrm{~kg} / \mathrm{m}^{2}(p<0.01)$. Sex and age did not have a significant impact on weight reduction. The number of patients with arterial hypertension, defined as blood pressure $>140 \mathrm{mmHg}$ systolic and $>90 \mathrm{mmHg}$ diastolic, decreased from 26 to nine. Blood pressure medication was able to be reduced or even discontinued in some patients (Table 2). The mean heart rate also decreased significantly.

\section{DXA findings}

Total body fat mass decreased significantly by $19 \%$ from $53.4 \pm 18.1 \mathrm{~kg}$ to $43.5 \pm 14.3 \mathrm{~kg}(p<0.01)$. Changes in fat distribution resulting from the 12 -week fasting phase are reported in Table 3.

\section{Echocardiographic findings}

Complete echocardiographic data sets were acquired in 30 patients. Image quality was compromised by high body weight. Grading of the image quality before weight loss was good in 10, moderate in eight, and poor in 12 patients. After 
Table 3 Dual-energy $X$-ray absorptiometry: fat mass before and after weight loss $(n=13)$

\begin{tabular}{|c|c|c|c|c|}
\hline \multirow[t]{2}{*}{$\overline{\text { Region }}$} & \multicolumn{2}{|l|}{ Fat mass (kg) } & \multirow{2}{*}{$\begin{array}{l}\text { Fat loss } \\
\text { (\%) }\end{array}$} & \multirow[t]{2}{*}{$p$-Value } \\
\hline & Week I & Week I2 & & \\
\hline Left arm & $2.6 \pm 0.6(52 \%)$ & $2.0 \pm 0.7(5 \mid \%)$ & 21 & $<0.01$ \\
\hline Right arm & $2.6 \pm 0.8(50 \%)$ & $2.1 \pm 0.8(48 \%)$ & 18 & $<0.01$ \\
\hline Trunk & $29.5 \pm 13.0(46 \%)$ & $24.7 \pm 9.7(43 \%)$ & 16 & $<0.01$ \\
\hline Left leg & $7.7 \pm 2.5(44 \%)$ & $6.8 \pm 2.1(44 \%)$ & 12 & $<0.01$ \\
\hline Right leg & $7.5 \pm 2.5(44 \%)$ & $6.7 \pm 2.1(44 \%)$ & 11 & $<0.01$ \\
\hline Head & $1.3 \pm 0.3(24 \%)$ & $1.2 \pm 0.2(25 \%)$ & 7 & $<0.01$ \\
\hline Total & $53.4 \pm 18.1(45 \%)$ & $43.5 \pm 14.3(43 \%)$ & 19 & $<0.01$ \\
\hline
\end{tabular}

Note: Data are presented as mean \pm standard deviation (percentage of fat).

weight loss, image quality improved and was good in 12 , moderate in nine, and poor in nine patients.

After weight loss, pulsed-wave Doppler of the mitral inflow showed a significant reduction of the A-wave velocity, from $65.8 \pm 19.2 \mathrm{~cm} / \mathrm{s}$ at week 1 to $57.0 \pm 16.8 \mathrm{~cm} / \mathrm{s}(p<0.01)$

A

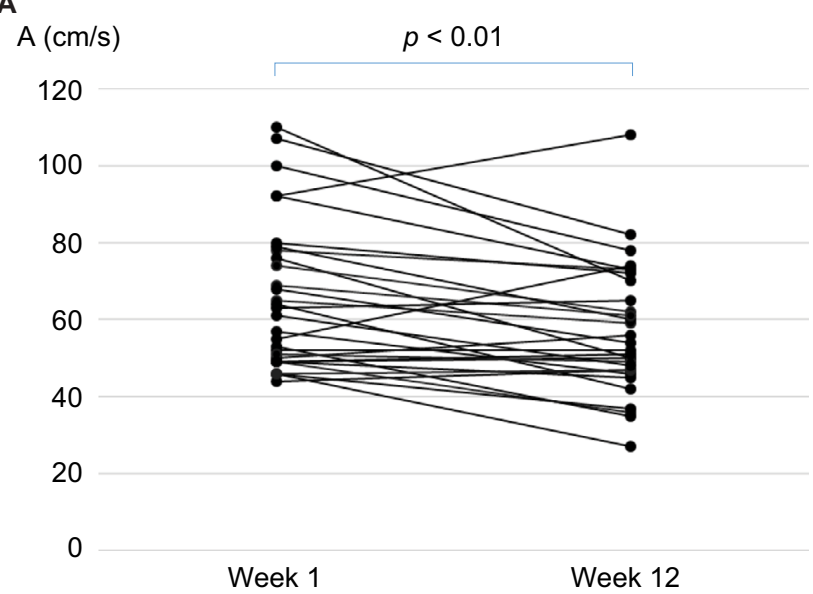

Figure 2 Changes of pulsed Doppler index A (A) and E/A ratio (B) after weight reduction.

A

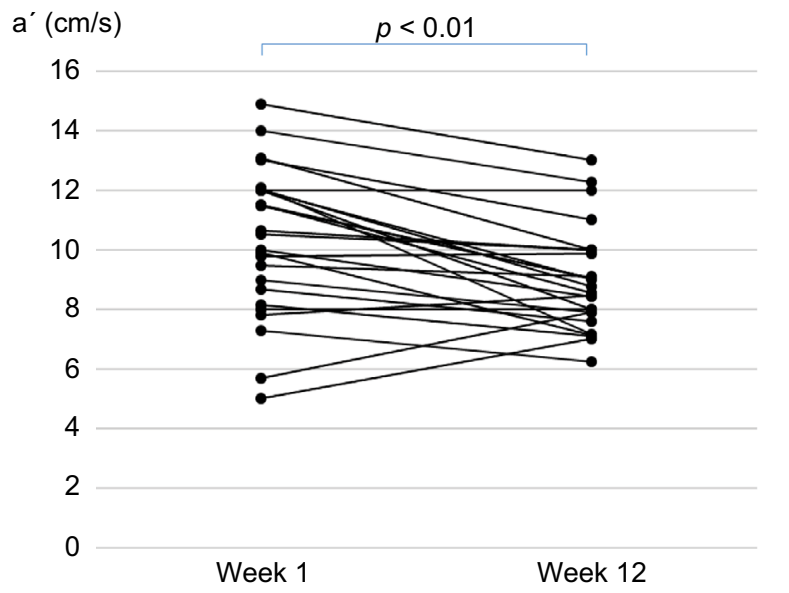

at week 12, and the E/A ratio increased significantly, from $1.2 \pm 0.4$ to $1.4 \pm 0.5(p<0.01)$ (Figure 2). TDI revealed a significant decrease of the $\mathrm{a}^{\prime}$-wave, from $10.3 \pm 2.3 \mathrm{~cm} / \mathrm{s}$ to $8.9 \pm 1.7 \mathrm{~cm} / \mathrm{s}(p<0.01)$, and a significant increase of the $\mathrm{e}^{\prime} / \mathrm{a}^{\prime}$ ratio, from $0.9 \pm 0.3$ to $1.1 \pm 0.3(p<0.04)$ (Figure 3). Weight reduction had no impact on other markers of diastolic dysfunction. Normal values for deceleration time and e'-wave are age-dependent. ${ }^{13}$ In the present study, deceleration time before and after weight loss was prolonged, at $250 \pm 60 \mathrm{~ms}$ and $248 \pm 46 \mathrm{~ms}$, respectively (normal value in age group 41-60 years: $181 \pm 19 \mathrm{~ms}$ ). The $\mathrm{e}^{\prime}$-wave was decreased, at $8.4 \pm 2.2 \mathrm{~cm} / \mathrm{s}$ and $9.1 \pm 1.8 \mathrm{~cm} / \mathrm{s}$, respectively (normal value in age group $41-60$ years: $12.2 \pm 2.3 \mathrm{~cm} / \mathrm{s})$. The $\mathrm{E} / \mathrm{e}^{\prime}$ ratio of $9.5 \pm 4.3$ decreased slightly to $8.3 \pm 2.0$, but the difference was not significant. We found no changes in cardiac structures and dimensions occurring secondary to weight loss after 12 weeks (Table 4).

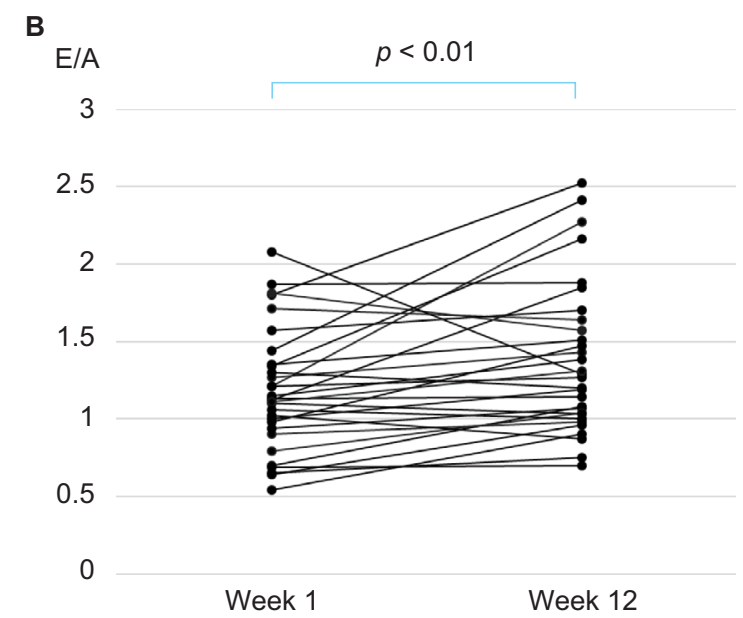

B

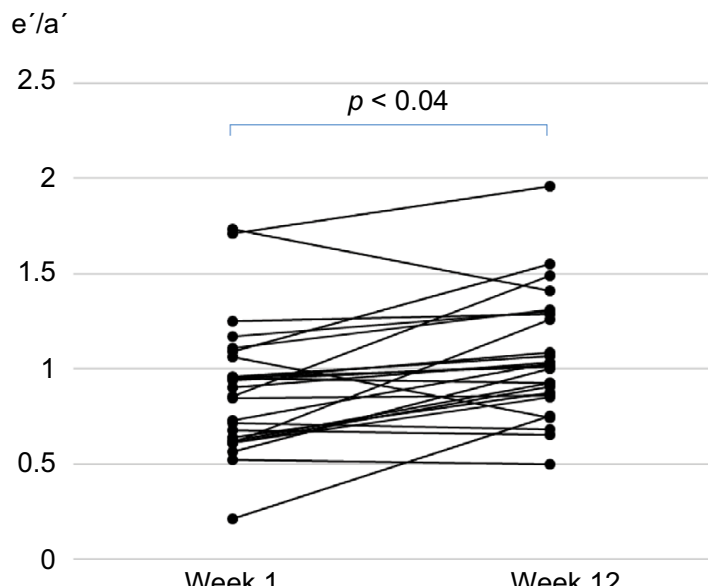

Figure 3 Changes of tissue Doppler index a' $(\mathbf{A})$ and e'/a' ratio $(\mathbf{B})$ after weight reduction. 
Table 4 Cardiac dimensions before and after weight loss

\begin{tabular}{llll}
\hline Parameter & Week I & Week I2 & p-Value \\
\hline LA diameter $(\mathrm{mm})$ & $4 \mathrm{I} \pm 5$ & $40 \pm 8$ & 0.54 \\
LA volume $(\mathrm{mL})$ & $57 \pm 19$ & $60 \pm 18$ & 0.20 \\
LV end-diastolic diameter & $48 \pm 10$ & $5 \mathrm{I} \pm 6$ & 0.20 \\
$(\mathrm{~mm})$ & & & \\
LV posterior wall $(\mathrm{mm})$ & $\mathrm{II} \pm 2$ & $\mathrm{II} \pm 2$ & 0.94 \\
$\begin{array}{l}\text { Interventricular septum } \\
(\mathrm{mm})\end{array}$ & $\mathrm{II} \pm 2$ & $\mathrm{II} \pm 2$ & 0.63
\end{tabular}

Note: Data are presented as mean \pm standard deviation.

Abbreviations: LA, left atrial; LV, left ventricular.

These findings suggest that diastolic LV function improved as a result of significant weight loss.

\section{Discussion}

Obesity is associated with structural and functional abnormalities of the heart. In agreement with other studies, we observed Doppler echocardiographic signs for diastolic dysfunction in patients with severe obesity. Interestingly, we found evidence of improvement in diastolic function in patients who achieved successful weight reduction after following a 12-week low-calorie diet. Weight reduction also correlated with a reduction in blood pressure and heart rate.

Diastolic dysfunction can be measured by analyzing the trans-mitral flow pattern using conventional Doppler echocardiography. Diastolic dysfunction with impaired myocardial relaxation is characterized by a decreased early (E-wave), but enhanced atrial LV filling (A-wave). Thus, atrial contraction basically compensates for the decrease in early passive filling and results in a lower E/A ratio. ${ }^{14}$ In a study by Chakko et al, the E/A ratio was decreased in patients with obesity due to an increase in the A-wave velocity, while the E-wave velocity was constant. ${ }^{15} \mathrm{In}$ our study, the trans-mitral E/A ratio increased significantly by $17.8 \%$ after 12 weeks of the diet, mainly due to a significant decrease in the A-wave velocity. Similar findings were reported after weight loss with a diet and an exercise program over 3-4 months. ${ }^{16,17}$ A study by Valezi and Machado showed a similar increase in the E/A ratio of $26.2 \%$ after weight loss 1 year after gastric bypass surgery. ${ }^{18}$

The TDI index $\mathrm{e}^{\prime} / \mathrm{a}^{\prime}$ correlates closely with LV stiffness. ${ }^{19}$ In our study, TDI revealed reduction of the $\mathrm{e}^{\prime} / \mathrm{a}^{\prime}$ ratio at baseline with significant increase after 12 weeks due to a decrease of the $a^{\prime}$-wave. In contrast, Yuksel et al reported no significant change of the $\mathrm{a}^{\prime}$ velocity after weight loss whereas the $\mathrm{e}^{\prime}$ velocity increased also resulting in a statistically significant increase of the $\mathrm{e}^{\prime} / \mathrm{a}^{\prime}$ ratio. ${ }^{16}$ In line with our findings, Fenk et al also found a significant improvement of the $\mathrm{e}^{\prime} / \mathrm{a}^{\prime}$ ratio after a 1-year weight reduction program comprising diet and lifestyle components. ${ }^{20}$
Compared to normal values reported in the literature, in our study, the diastolic trans-mitral deceleration time was prolonged, and the $\mathrm{e}^{\prime}$-wave velocity was decreased indicating impaired diastolic function at baseline and at the end of the fasting phase. ${ }^{13}$ A reduction of the e $\phi$-wave velocity in people with obesity has also been reported in other studies. ${ }^{15,21}$

A parameter widely used to measure diastolic dysfunction is the $\mathrm{E} / \mathrm{e}^{\prime}$ ratio, which can predict $\mathrm{LV}$ filling pressures. An $E / e^{\prime}$ ratio ranging from 8 to 15 is considered a suggestive but nondiagnostic evidence of diastolic LV dysfunction. ${ }^{22}$ In our data, mean E/e' values were only modestly elevated (between 8 and 10) at baseline and reduced after weight loss, but the difference was not statistically significant. Other studies showed a significant reduction of the E/e' ratio after bariatric surgery or nonsurgical weight loss strategies. ${ }^{16,23}$

In moderate-to-severe cases of obesity, increased cardiac output due to the high metabolic activity of excessive fat may lead to left atrial and LV dilation, increased LV wall stress, and compensatory (eccentric) LV hypertrophy. ${ }^{24}$ In the present study, mean LV diameter and thickness of the LV wall were normal at week 1 and remained unchanged after 12 weeks on the diet. Other studies reported a decrease in LV dilatation, hypertrophy, and mass after weight reduction interventions with longer follow-up periods. ${ }^{25-27}$

Lifestyle and diet therapies have demonstrated some cardiovascular benefits. Data from a number of recent metaanalyses, however, suggest that bariatric operations result in greater improvement of cardiovascular risk parameters than other weight loss therapies. ${ }^{28}$ However, no randomized controlled trials currently exist comparing the effects of bariatric surgery with standardized nonsurgical treatments, specifically focusing on cardiovascular end points.

In our study, the DXA measurement showed a significant reduction of total fat mass after weight loss, but overall, the regional body composition did not change. Other authors have emphasized that remarkable individual differences exist in regional body fat accumulation and such variation in regional adiposity may determine the cardiovascular risk. Therefore, BMI or total body fat and the magnitude of weight loss may not represent the most relevant therapeutic targets in the management of obesity. ${ }^{29}$ Excess abdominal fat is known to be associated with increased risk of atherosclerosis and cardiovascular mortality. ${ }^{30,31}$ Several intervention studies using a combination of physical activity and moderate caloric restriction have reported a preferential mobilization of visceral and ectopic fat beyond that which could be predicted due to weight loss. ${ }^{32,33}$ 


\section{Limitations}

The present study did have some limitations that deserve comment. First, we were unable to demonstrate cardiac changes due to obesity such as LV hypertrophy and enlargement or atrial dilatation as described by other authors. However, patients in our group were relatively young (mean age 45 years) in terms of the risk of other causes of structural cardiac abnormalities. Second, criteria measured by conventional Doppler echocardiography in order to determine diastolic dysfunction are in part heart rate, preload, and afterload dependent and are subject to change within any given patient. Third, echocardiographic measurements in people with obesity may be error-prone or imprecise.

\section{Conclusion}

Obesity is associated with diastolic dysfunction, which can be measured by conventional Doppler and tissue Doppler echocardiography. A 12-week low-calorie diet with successful weight loss can reduce blood pressure and heart rate and partially normalize diastolic dysfunction.

\section{Acknowledgments}

This research did not receive any specific grant from funding agencies in the public, commercial, or not-for-profit sectors. The authors thank Janet Collins (ICCC Rhein-Main, Frankfurt, Germany) for proofreading and correcting the final manuscript.

\section{Author contributions}

All authors contributed toward data analysis, drafting and critically revising the paper and agree to be accountable for all aspects of the work.

\section{Disclosure}

The authors report no conflicts of interest in this work.

\section{References}

1. Loehr LR, Rosamond WD, Poole C, et al. Association of multiple anthropometrics of overweight and obesity with incident heart failure: the Atherosclerosis Risk in Communities study. Circ Heart Fail. 2009; 2(1): $18-24$.

2. Whitlock G, Lewington S, Sherliker P, et al; Prospective Studies Collaboration. Body-mass index and cause-specific mortality in 900000 adults: collaborative analyses of 57 prospective studies. Lancet. 2009; 373(9669):1083-1096.

3. Preis SR, Massaro JM, Robins SJ, et al. Abdominal subcutaneous and visceral adipose tissue and insulin resistance in the Framingham heart study. Obesity (Silver Spring). 2010;18(11):2191-2198.

4. Peterson LR, Waggoner AD, Schechtman KB, et al. Alterations in left ventricular structure and function in young healthy obese women: assessment by echocardiography and tissue Doppler imaging. $J \mathrm{Am}$ Coll Cardiol. 2004;43(8):1399-1404.
5. Wong CY, O’Moore-Sullivan T, Leano R, Byrne N, Beller E, Marwick TH. Alterations of left ventricular myocardial characteristics associated with obesity. Circulation. 2004;110(19):3081-3087.

6. Owan TE, Hodge DO, Herges RM, Jacobsen SJ, Roger VL, Redfield MM. Trends in prevalence and outcome of heart failure with preserved ejection fraction. $N$ Engl J Med. 2006;355(3):251-259.

7. Mahajan R, Lau DH, Sanders P. Impact of obesity on cardiac metabolism, fibrosis, and function. Trends Cardiovasc Med. 2015;25(2):119-126.

8. Heneghan HM, Meron-Eldar S, Brethauer SA, Schauer PR, Young JB. Effect of bariatric surgery on cardiovascular risk profile. Am J Cardiol. 2011;108(10):1499-1507.

9. Poirier P, Cornier MA, Mazzone T, et al; American Heart Association Obesity Committee of the Council on Nutrition, Physical Activity, and Metabolism. Bariatric surgery and cardiovascular risk factors: a scientific statement from the American Heart Association. Circulation. 2011;123(15):1683-1701.

10. de las Fuentes L, Waggoner AD, Mohammed BS, et al. Effect of moderate diet-induced weight loss and weight regain on cardiovascular structure and function. J Am Coll Cardiol. 2009;54(25):2376-2381.

11. Karimian S, Stein J, Bauer B, Teupe C. Impact of severe obesity and weight loss on systolic left ventricular function and morphology: assessment by 2-dimensional speckle-tracking echocardiography. $J$ Obes. 2016;2016:2732613.

12. Yamada H, Oki T, Tabata T, Iuchi A, Ito S. Assessment of left ventricular systolic wall motion velocity with pulsed tissue Doppler imaging: comparison with peak $\mathrm{dP} / \mathrm{dt}$ of the left ventricular pressure curve. $J \mathrm{Am}$ Soc Echocardiogr. 1998;11(5):442-449.

13. Nagueh SF, Appleton CP, Gillebert TC, et al. Recommendations for the evaluation of left ventricular diastolic function by echocardiography. Eur J Echocardiogr. 2009;10(2):165-193.

14. Appleton CP, Hatle LK, Popp RL. Relation of transmitral flow velocity patterns to left ventricular diastolic function: new insights from a combined hemodynamic and Doppler echocardiographic study. $J$ Am Coll Cardiol. 1988;12(2):426-440.

15. Chakko S, Mayor M, Allison MD, Kessler KM, Materson BJ, Myerburg RJ. Abnormal left ventricular diastolic filling in eccentric left ventricular hypertrophy of obesity. Am J Cardiol. 1991;68(1):95-98.

16. Yuksel IO, Akar Bayram N, Koklu E, et al. Assessment of impact of weight loss on left and right ventricular functions and value of tissue Doppler echocardiography in obese patients. Echocardiography. 2016;33(6):854-861.

17. Jonker JT, Snel M, Hammer S, et al. Sustained cardiac remodeling after a short-term very low calorie diet in type 2 diabetes mellitus patients. Int J Cardiovasc Imaging. 2014;30(1):121-127.

18. Valezi AC, Machado VH. Morphofunctional evaluation of the heart of obese patients before and after bariatric surgery. Obes Surg. 2011;21(11): 1693-1697.

19. Kasner M, Westermann D, Steendijk P, et al. Utility of Doppler echocardiography and tissue Doppler imaging in the estimation of diastolic function in heart failure with normal ejection fraction: a comparative Doppler-conductance catheterization study. Circulation. 2007; 116(6):637-647.

20. Fenk S, Fischer M, Strack C, et al. Successful weight reduction improves left ventricular diastolic function and physical performance in severe obesity. Int Heart J. 2015;56(2):196-202.

21. Wierzbowska-Drabik K, Chrzanowski L, Kapusta A, et al. Severe obesity impairs systolic and diastolic heart function - the significance of pulsed tissue Doppler, strain, and strain rate parameters. Echocardiography. 2013;30(8):904-911.

22. Paulus WJ, Tschöpe C, Sanderson JE, et al. How to diagnose diastolic heart failure: a consensus statement on the diagnosis of heart failure with normal left ventricular ejection fraction by the Heart Failure and Echocardiography Associations of the European Society of Cardiology. Eur Heart J. 2007;28(20):2539-2550.

23. Leung M, Xie M, Durmush E, Leung DY, Wong VW. Weight loss with sleeve gastrectomy in obese type 2 diabetes mellitus: impact on cardiac function. Obes Surg. 2016;26(2):321-326. 
24. Alpert MA. Obesity cardiomyopathy: pathophysiology and evolution of the clinical syndrome. Am J Med Sci. 2001;321(4):225-236.

25. Algahim MF, Lux TR, Leichman JG, et al. Progressive regression of left ventricular hypertrophy two years after bariatric surgery. Am J Med. 2010;123(6):549-555.

26. Owan T, Avelar E, Morley K, et al. Favorable changes in cardiac geometry and function following gastric bypass surgery: 2-year follow-up in the Utah obesity study. J Am Coll Cardiol. 2011;57(6): 732-739.

27. Alpert MA, Omran J, Mehra A, Ardhanari S. Impact of obesity and weight loss on cardiac performance and morphology in adults. Prog Cardiovasc Dis. 2014;56(4):391-400.

28. Ashrafian H, le Roux CW, Darzi A, Athanasiou T. Effects of bariatric surgery on cardiovascular function. Circulation. 2008;118(20):2091-2102.
29. Després JP. Body fat distribution and risk of cardiovascular disease: an update. Circulation. 2012;126(10):1301-1313.

30. Gasteyger C, Tremblay A. Metabolic impact of body fat distribution. J Endocrinol Invest. 2002;25(10):876-883.

31. Dagenais GR, Yi Q, Mann JF, Bosch J, Pogue J, Yusuf S. Prognostic impact of body weight and abdominal obesity in women and men with cardiovascular disease. Am Heart J. 2005;149(1):54-60.

32. Ross R, Dagnone D, Jones PJ, et al. Reduction in obesity and related comorbid conditions after diet-induced weight loss or exercise-induced weight loss in men. A randomized, controlled trial. Ann Intern Med. 2000;133(2):92-103.

33. Borel AL, Nazare JA, Smith J, et al. Visceral and not subcutaneous abdominal adiposity reduction drives the benefits of a 1-year lifestyle modification program. Obesity (Silver Spring). 2012;20(6):1223-1233.
Diabetes, Metabolic Syndrome and Obesity: Targets and Therapy is an international, peer-reviewed open-access journal committed to the rapid publication of the latest laboratory and clinical findings in the fields of diabetes, metabolic syndrome and obesity research. Original research, review, case reports, hypothesis formation, expert opinion and commentaries are all considered for publication. The manuscript management system is completely online and includes a very quick and fair peer-review system, which is all easy to use. Visit http://www.dovepress.com/testimonials.php to read real quotes from published authors.

Submit your manuscript here: https://www.dovepress.com/diabetes-metabolic-syndrome-and-obesity-targets-and-therapy-journal 